\title{
Research article \\ Novel urinary markers: taurine, dopamine and L-fucose levels in predicting neonatal seizures
}

\author{
Varashree B.S ${ }^{1}$, Sravya Poduri ${ }^{1}$, Leslie Edward Lewis ${ }^{2}$, Vijetha Shenoy Belle ${ }^{1}$ \\ ${ }^{1}$ Department of Biochemistry, Kasturba Medical College, Manipal, Manipal Academy of Higher Education, Manipal, \\ Karnataka, India, 576104 \\ ${ }^{2}$ Department of Paediatrics, Kasturba Medical College, Manipal, Manipal Academy of Higher Education, Manipal, Karnataka, \\ India, 576104
}

(Received: July $2021 \quad$ Revised: November $2021 \quad$ Accepted: December 2021)

Corresponding author: Vijetha Shenoy Belle. Email: vijetha.shenoy@ manipal.edu

\begin{abstract}
Introduction and Aim: Neonatal seizure is an age specific neurological emergency. Their unique pathophysiological mechanism has become subject of interest for many research studies. The recurrence risk for seizures is high during neonatal period and currently used treatment strategies have limited efficacy in preventing it. From past decades although the treatment has not changed, there is a gradual progress in various mechanisms that are involved in generation of seizures and their response to anti-epileptics. With the emergence of new biochemical parameters for risk assessment in patients with seizures, there is a strong need for their comparative evaluation in order to evaluate their potential clinical application. So, this study was carried out to compare the urine levels of taurine, dopamine and fucose in assessing their role in mechanism of seizure.
\end{abstract}

Materials and Methods: After obtaining ethical approval and consent from parents total 43 neonates, urine taurine, dopamine and fucose were measured in 24 cases of seizures and 19 apparently healthy normal controls. Dopamine and Taurine were measured using ELISA and L-fucose by Dische and Shettles method.

Results: The median level of urine fucose was significantly higher in male neonates, taurine was significantly decreased in cases compared to that of controls. Males had higher preponderance to develop seizures. The median levels of urine dopamine were high in cases compared to controls but has not showed any significance.

Conclusion: Amino acid like taurine, carbohydrate moiety like fucose and a neuromodulator like dopamine may have a mechanistic role in development of seizures in neonatal period.

Keywords: Gamma amino butyric acid; neuromodulator; neonatal seizure; fucose; dopamine; taurine.

\section{INTRODUCTION}

$\mathrm{T}$ he biochemical interactions between genes and environment determine life. These interactions in higher animals like humans are under the control of many neurotransmitters, hormones \& other mediators. So the programming of the brain in the prenatal and early postnatal period determines their functional tolerance towards life (1). The most important neurological emergency that occurs during the neonatal period is seizures. Although it is critical to determine the exact cause, Hypoxic Ischemic Encephalopathy (HIE) is known to be most common for seizure occurrence. In Hypoxic Ischemic Encephalopathy pathogenesis there is overactivity of excitatory neurotransmitters and this is due to hypoxia during the perinatal period and immature systems to balance the internal environment. Role of inhibitory amino acids like taurine, GABA, and excitatory amino acid-like glutamate was determined in regions of the frontal cortex, hypothalamus, and cerebellum. In brain hypoxia, there is a significant elevation of excitatory amino acids in the cerebellar granular layer (2).

Taurine is required for organ development in the fetus and renewal of nutrient transport epithelium of placental syncytiotrophoblast. In human pregnancy, it is a conditionally essential amino acid. The fetal and placental demand of taurine is regulated by taurine transporter (TauT). The placenta lacks the enzyme required for the synthesis of taurine (3). The fetal requirement of taurine is met through Tau $\mathrm{T}, \mathrm{a} \mathrm{Na}^{+}$ dependent taurine transporter that is expressed on the microvillous plasma membrane of the syncytiotrophoblast. TauT accumulates taurine and this intracellular accumulation causes taurine efflux through taurine permeable anion channels in the fetus (4).

During the development of an immature brain, any hypoxic-ischemic insult can cause the accumulation of polymorphonuclear cells (PMN), natural killer cells (NK), astroglial cells, and mast cells. The activation of these cells causes changes in toll-like receptors (TLR's) and excitatory amino acids by producing reactive oxygen species (ROS) leading to secondary brain death $(5-7)$. Systemic fetal inflammation is the most important reason for preterm birth and may indirectly contribute to neonatal morbidity $(8,9)$. During seizure excitatory amino acid glutamate causes the increased tonic activity of dopamine. The excitability in neuronal circuits is regulated by several neuromodulators. The seizure initiation and frequency 
are under the control of neuromodulatory inputs that connect the brain to other hyperexcitable circuits (10). During the interictal period of seizure activity dopamine highly interacts with glutamate leading to an increased initiation and recurrence seizure effect of glutamate or over inactivation of dopamine (11) causing depolarization block in the midbrain. Hence kindling effect of glutamate secondary dopamine dysfunction leads to brain excitation. The glycosylation pattern of glycoconjugates related to GDP-fucose can causes alterations in the progression of normal pregnancy (12).

Thus, these parameters may have a role in identifying events that precede seizures. There is a need to study the urine levels of markers that have a role in a neonatal seizure so that it can ease in sample collection by non-invasive method and levels significantly help the paediatrician in treatment policy of neonatal seizures.

The objectives of the study were to evaluate the role of urine levels of neuromodulators like dopamine, taurine \& L-fucose in neonates with seizures.

\section{MATERIALS AND METHODS}

The prospective case-control study was carried out after obtaining approval from the Institutional Ethics Committee between June 2016 to December 2018 (The ethical clearance certificate number: IEC 443/2015). The urine samples were collected from Department of Neonatology/Paediareics, Kasturba Medical College, Manipal and samples were analysed at Department of Biochemistry, Kasturba Medical College, Manipal.

Written consent was taken from the parents of each subject. Subjects of both genders with less than 28 days of life along with seizures of both known and unknown cause were selected as cases and, age and sex-matched healthy individuals in the age group of less than 28 days but not suffering from any medical illness were considered as controls. Due to difficulty in sample collection from neonates and time bound study could not meet the required number.

\section{Inclusion criteria for cases}

a) Subjects with seizures of both known and unknown cause.

b) Subjects of both genders in the age group of $<28$ days.

\section{Inclusion criteria for controls}

Age and sex matched healthy individuals in the age group of less than 28 days but not suffering from any medical illness.

\section{Exclusion criteria for cases}

a) Patients > 28 days old with or without seizures b) Patients suffering exclusively from neurological illness, renal, liver, respiratory, cardiac and other systemic disorders.

\section{Exclusion criteria for controls}

Subjects $>28$ days without any medical illness.

The sample size was 80 anticipating a difference of 10 in the mean levels of urine dopamine, taurine, and Lfucose with S.D. of 15 for a power of $80 \%$, 95\% confidence level 40 subjects in each group.

\section{Sample size calculation}

$\mathrm{n}=2[(\mathrm{Z} \alpha+\mathrm{Z} \beta) \mathrm{S}] 2 / 2[\mathrm{~d}] 2=45$

$Z \alpha=$ value at specified confidence level

$Z \beta=$ value at specified power

$\mathrm{S}=$ pooled standard deviation of observations of 2 samples

$\mathrm{d}=$ clinically significant difference

The estimated sample size is 40 for cases and 40 for controls. Considering the limitation of difficulty in collecting a urine sample from neonates 24 cases and 19 controls were recruited under study. $5 \mathrm{ml}$ urine sample was collected randomly into a sterile container using minisac neonatal urine collection bag and stored at $-80^{\circ} \mathrm{C}$ in Eppendorf tubes until use. Taurine (cloud clone corp) and dopamine (DLD Diagnostika GMBH) were estimated using the ELISA kit. Urine fucose is estimated by using Dische and Shettles method (13) The statistical analysis was done using non-parametric tests since a normal distribution curve was not found. A $p$ value $<0.05$ was considered significant.

\section{RESULTS}

Out of 43 subjects that have been recruited in to study 24 were suffering from seizures and the remaining 19 were apparently healthy controls.

Among 43 study subjects, 14 were females and 29 were male neonates. Out of 29 males, $16(55.17 \%)$ had seizures, and the remaining 13(44.8\%) were normal. Out of 14 females, only $8(42.1 \%)$ had seizures, and the remaining $6(31.5 \%)$ were normal (Table 1$)$ Thus, we found that male neonates were more prone to suffer from seizures than female neonates.

Table 1: Gender distribution among cases and controls

\begin{tabular}{|c|c|c|c|}
\hline & Controls & Cases & Total \\
\hline Males & $13(44.8 \%)$ & $16(55.17 \%)$ & 29 \\
\hline Females & $6(42.8 \%)$ & $8(57.1 \%)$ & 14 \\
\hline Total & $\mathbf{1 9}$ & $\mathbf{2 4}$ & $\mathbf{4 3}$ \\
\hline
\end{tabular}

Fig. 1 shows, median level of urine taurine in controls was $7.85 \mathrm{ng} / \mathrm{mL}$, and the median level of the same in cases was $57.0 \mathrm{ng} / \mathrm{mL}$ which was statistically significant $(\mathrm{p}=<0.001)$. 


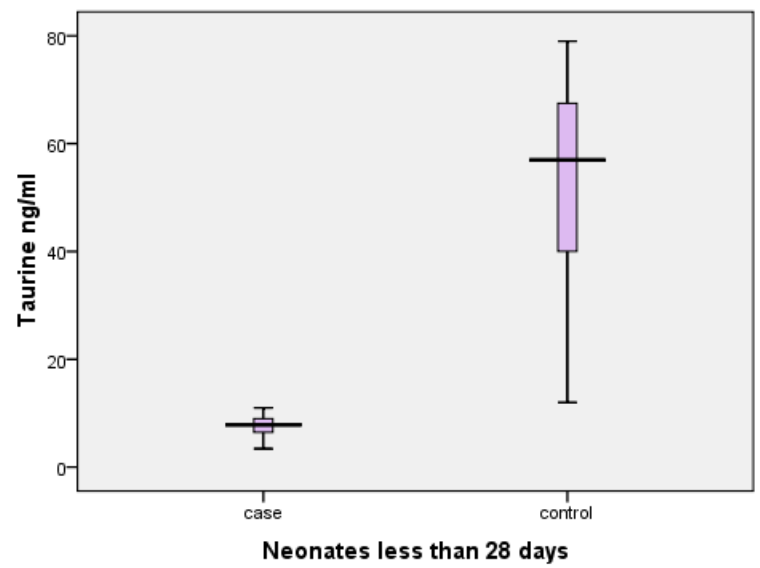

Fig. 1: Urine taurine levels in cases and controls

Fig. 2 shows the Median value of urine dopamine in controls was $201.6 \mathrm{ng} / \mathrm{mL}$ and in cases, it was $341.8 \mathrm{ng} / \mathrm{mL}$. Increased urine dopamine in cases was not statistically significant compared to controls $(\mathrm{p}=0.074)$

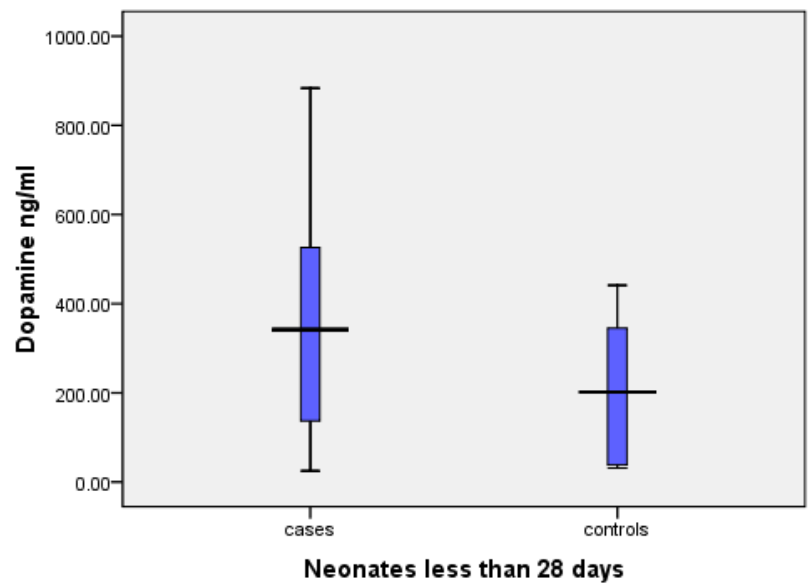

Fig. 2: Urine dopamine among controls and cases

The median value of Urine fucose in controls was $2.36 \mu \mathrm{mol} / \mathrm{gm}$ creatinine and in cases, it was $48.9 \mu \mathrm{mol} / \mathrm{gm}$ creatinine. Increased urine fucose in cases is statistically significant $(\mathrm{p}<0.001)$ than controls (Table 2$)$.

Table 2: Urine fucose levels in cases and controls

\begin{tabular}{|c|c|c|c|}
\hline \multicolumn{4}{|c|}{ Urine Fucose $(\boldsymbol{\mu m o l} / \mathbf{g m}$ creatinine $)$} \\
\cline { 1 - 3 } $\boldsymbol{\mu}$ GGroups & Median & Interquartile range & p value* \\
\cline { 1 - 3 } Controls & 2.36 & $(1.54,5.50)$ & $<\mathbf{0 . 0 0 1}$ \\
\cline { 1 - 3 } Cases & 48.9 & $(24.45,1.06)$ & \\
\hline
\end{tabular}

*Non-parametric test: Mann- Whitney U

Further statistical analysis was done between different study groups

Table 3: Comparison of urinary taurine, fucose and dopamine in different study groups

\begin{tabular}{|c|c|}
\hline $\begin{array}{c}\text { Comparison of urine taurine levels between different } \\
\text { study groups }\end{array}$ & p value \\
\hline Cases \& controls & $<0.001^{*}$ \\
\hline Male cases \& male controls & $<0.001^{*}$ \\
\hline Female cases \& female controls & $=0.001$ \\
\hline $\begin{array}{c}\text { Comparison of urine fucose levels between different study } \\
\text { groups }\end{array}$ & p value \\
\hline Cases \& controls & $<0.001^{*}$ \\
\hline Male cases \& male controls & $<0.001^{*}$ \\
\hline Female cases \& female controls & $=0.001^{*}$ \\
\hline $\begin{array}{c}\text { Comparison of urine dopamine levels between different } \\
\text { study groups }\end{array}$ & $\mathbf{p}$ value \\
\hline Cases \& controls & $0.074^{\mathrm{NS}}$ \\
\hline Male cases \& male controls & $0.273^{\mathrm{NS}}$ \\
\hline Female cases \& female controls & $0.197^{\mathrm{NS}}$ \\
\hline
\end{tabular}




\section{DISCUSSION}

Seizures among neonates are most commonly due to perinatal hypoxia in the first 24-48 hours of postnatal life. Due to hypoxia the high-energy phosphate stores and extracellular release of excitatory amino acids of the hippocampal region like glutamate undergo change and become toxic to the brain (14). In early excitatory neurotransmission predominate in neurons of the cerebral cortex and limbic structures (15). Extracellular glutamate accumulates and there is an increased expression of glutamate tRNA ligase (GluRs), transporters, and ion channels in hypoxic tissue (16) in neonatal period inhibitory mechanisms are underdeveloped compared to later life. There is a gradual increase of inhibitory neurotransmitter GABA until the fourth postnatal week in the neonatal rat (17, 18). During early postnatal life GABA is an excitatory neurotransmitter in contrast to its hyperpolarizing action in later life. In immature neurons, due to lack of chloride exporter $\mathrm{KCC} 2$, there is an increased accumulation of intracellular chloride concentration leading to excitation of GABAergic neurons (19).

Certain Neuropeptides, hormones, and their receptors also account for the development of neonatal seizures. Corticotrophin-releasing hormone (CRH) levels are high in the perinatal period that contributes to the development of neonatal seizures (20). Adrenocorticotrophic hormone (ACTH) which is known to be efficient in infantile spasms downregulates the expression of the $\mathrm{CRH}$ gene suggests neuropeptides modulation in the development of seizures (21).

The emergence of seizures could not be just due to depletion of GABA but also can be due to changes in other active amino acids like glutamate (Glu), glycine (Gly), and taurine (Tau). The concentration of Tau was found to be significantly lower in neonatal rats that are vitamin B6 restricted. The brain regions like substantia niagra, Pons, and medulla are highly vulnerable to seizures with loss of Tau while the hippocampus seems to be resistant (22).

In this study, there is an increase in taurine level among controls compared to cases (fig. 1) gender matched cases showed decreased taurine levels than controls (table 3) suggesting that deficiency of it might be one of the causes for developing seizures among cases.

Taurine is an essential amino acid in new-borns for their development and hence its transport into the foetus is important during the development of the embryo. The transport mechanism in the early embryonic period and the expression of its protein pattern is still not known. Studies showed that both TauT and Cysteine sulfinate decarboxylase (CSD) mRNA began to appear at $48 \mathrm{~h}$ and $12 \mathrm{~h}$ respectively during times of development (22). Taurine has a protective role in the central nervous system against the excitotoxicity of glutamate by inhibiting glutamate-induced calcium increase. It also prevented glutamate-induced cellular apoptosis by downregulating BCL 2 and up-regulating BAX. Glutamate causes the death of neurons by increasing intracellular levels of calcium and sodium followed by activation of phospholipases, proteases, endonucleases, and formation of reactive oxygen species causing cell death.

In the present study, the level of urinary dopamine was increased in cases compared to controls (fig 2). Dopamine D1 receptor signalling is pro epileptogenic and D2 receptors are anti epileptogenic and these D2 receptors have an inhibitory effect on excitable hippocampal neurons. Certain antipsychotics that have D2 like antagonistic action decreased the seizure threshold in patients who had a history of seizures. The opposite action of D1 and D2receptors signalling in seizures is due to an interaction between glutamate and dopamine, as seen in animal studies in which D1 receptors upon activation during seizure has activated glutamate receptor (23). During seizures, there is impairment in dopamine level and its metabolites levels vary depending on the type of seizures.

In our study fucose levels were increased in cases (table 2) and gender matched cases showed increased fucose levels than controls (table 3 ), suggesting its role in neuronal inflammation that could provoke excitability of certain neurons leading to seizures. Fucosylation of certain glycoprotein has a role in memory consolidation. A study has shown quantitative changes in fucose turnover rates of certain brain regions (24). L fucose is known to have inositol uptake activity. Lithium inhibits the enzymatic degradation of inositol triphosphate (IP3) noncompetitively leading to decreased availability of inositol that is needed for the generation of secondary messenger like diacylglycerol (DAG). L-fucose was shown to have increased the activity of lithium (25). Glial cells and astrocytes in the brain uptake inositol more rapidly. Inhibition of inositol uptake by fucose increases the seizure promoting effect of lithium (26).

\section{CONCLUSION}

The altered levels of monoamine neurotransmitters and certain neuromodulators that are expressed during the early stages of embryo development have a significant effect on receptor expression, synaptic connections, and overall brain programming thus definitely have a role in the pathophysiological mechanism of seizures and further causing long term neurological, learning and behavioural problems. Thus amino acid-like taurine, carbohydrate moiety like fucose and a neuromodulator like dopamine has a mechanistic role in the development of seizures in the neonatal period. Measuring these parameters may aid in the treatment plan for the paediatrician and better outcome of neonatal seizures. 


\section{CONFLICT OF INTEREST}

Authors declare that there is no conflict of interest.

\section{REFERENCES}

1. Marques, A. H., O'Connor, T. G., Roth, C., Susser, E., Bjørke-Monsen, A. L. The influence of maternal prenatal and early childhood nutrition and maternal prenatal stress on offspring immune system development and neurodevelopmental disorders. Front Neurosci. 2013; 31(7): 120.

2. Basavarajappa, B. S. Neuropharmacology of the Endocannabinoid Signaling System-Molecular Mechanisms, Biological Actions and Synaptic Plasticity. Curr Neuropharmacol. 2007; 5(2): 81-97.

3. Desforges, M., Ditchfield, A., Hirst, C. R., Pegorie, C., Martyn-Smith, K., Sibley, C. P., et al., Reduced placental taurine transporter (TauT) activity in pregnancies complicated by pre-eclampsia and maternal obesity. Adv Exp Med Biol. 2013; 776: 81-91.

4. Desforges, M., Parsons, L., Westwood, M., Sibley, C. P., Greenwood, S. L. Taurine transport in human placental trophoblast is important for regulation of cell differentiation and survival. Cell Death and Disease. 2013; 4: e559.

5. Mosley, R. L., Benner, E. J., Kadiu, I., Thomas, M., Boska, M. D., Hasan, K., et al., Neuroinflammation, oxidative stress and the pathogenesis of parkinson's disease. Clin Neurosci Res. 2006; 6(5): 261-281.

6. Hagberg, H., Mallard, C., Ferriero, D. M., Vannucci, S. J., Levison, S. W., Vexler, Z. S., et al., The role of inflammation in perinatal brain injury. Nat Rev Neurol. 2015; 11(4): 192208.

7. Johnston, M. V. Excitotoxicity in perinatal brain injury. Brain Pathol. 2005; 15(3): 234-240.

8. Okazaki, K., Nishida, A., Kimura, H. Inflammatory Mediators in Neonatal Asphyxia and Infection. In: Buonocore G., Bracci R., Weindling M. (eds) Neonatology. Springer, Cham. 2016; https://doi.org/10.10 07/978-3-319-18159-2_248-1

9. Alvarez-Díaz, A., Hilario, E., de Cerio, F. G., Valls-i-Soler, A., Alvarez-Díaz, F. J. Hypoxic-ischemic injury in the immature brain--key vascular and cellular players. Neonatology. 2007; 92(4): 227-235.

10. Hablitz, J. J. Regulation of circuits and excitability: implications for epileptogenesis. Epilepsy Curr. 2004; 4(4): 151-153.

11. Scharfman, H. E. The neurobiology of epilepsy. Curr Neurol Neurosci Rep. 2007; 7(4): 348-354.

12. Maverakis, E., Kim, K., Shimoda, M., Gershwin, M. E., Patel, F., Wilken, R., et al., Glycans in the immune system and The Altered Glycan Theory of Autoimmunity: a critical review. J Autoimmun. 2015; 57: 1-13.

13. Kumar, S., Saxena, M., Srinivas, K., Singh, V. K. Fucose: A biomarker in grading of oral cancer. Natl J Maxillofac Surg. 2015; 6(2): 176-179.

14. Yager, J. Y., Armstrong, E. A., Miyashita, H., Wirrell, E. C. Prolonged neonatal seizures exacerbate hypoxic-ischemic brain damage: correlation with cerebral energy metabolism and excitatory amino acid release. Dev Neurosci. 2002; 24(5): 367-381.

15. Lucassen, P. J., Pruessner, J., Sousa, N., Almeida, O. F., Van Dam, A. M., Rajkowska, G., et al., Neuropathology of stress. Acta Neuropathol. 2014; 127(1): 109-135.

16. Shimoda, L. A., Polak, J. Hypoxia. 4. Hypoxia and ion channel function. Am J Physiol Cell Physiol. 2011; 300(5): C951-C967.

17. Buckler, K. J., Vaughan-Jones, R. D., Peers, C., Nye, P. C. Intracellular $\mathrm{pH}$ and its regulation in isolated type I carotid body cells of the neonatal rat. J Physiol. 1991; 436: 107-129.

18. Gu, X. Q., Haddad, G. G. Decreased neuronal excitability in hippocampal neurons of mice exposed to cyclic hypoxia. $\mathbf{J}$ Appl Physiol (1985). 2001; 91(3): 1245-1250.
19. Banasiak, K. J., Burenkova, O., Haddad, G. G. Activation of voltage-sensitive sodium channels during oxygen deprivation leads to apoptotic neuronal death. Neuroscience. 2004; 126(1): 31-44.

20. Bernhardt, W. M., Warnecke, C., Willam, C., Tanaka, T., Wiesener, M. S., Eckardt, K. U. Organ protection by hypoxia and hypoxia-inducible factors. Methods Enzymol. 2007; 435: 221-245.

21. Le Magueresse, C., Monyer, H. GABAergic interneurons shape the functional maturation of the cortex. Neuron. 2013; 77(3): 388-405.

22. Chepkova, A. N., Sergeeva, O. A., Haas, H. L. Long-lasting enhancement of corticostriatal transmission by taurine: role of dopamine and acetylcholine. Cell Mol Neurobiol 2005; 25: 767-776.

23. Bozzi, Y., Borrelli, E. The role of dopamine signaling in epileptogenesis. Front Cell Neurosci. 2013; 7:157.

24. Lubrich, B., van Calker, D. Inhibition of the high affinity myo-inositol transport system: a common mechanism of action of antibipolar drugs? Neuropsychopharmacol. 1999; 21: 519-529.

25. Einat, H., Kofman, O., Itkin, O., Lewitan, R., Belmaker, R. H. Augmentation of lithium's behavioral effect by inositol uptake inhibitors. J Neural Transm 1998; 105: 31-38.

26. Wolfson, M., Bersudsky, Y., Hertz, E., Berkin, V., Zinger, E., Hertz, L. A Model of Inositol Compartmentation in Astrocytes Based Upon Efflux Kinetics and Slow Inositol Depletion after Uptake Inhibition Neurochemical Research 2000; 25(7): 977-998. 